Article

\title{
Analysis of the Effect of a Vertical Magnetic Field on Melt Convection and Oxygen Transport During Directional Solidification of Multi-Crystalline Silicon by Numerical Simulation
}

\author{
Botao Song ${ }^{1,2}$, Yufeng Luo ${ }^{1,2,3}$, Senlin Rao ${ }^{2,4}$, Fayun Zhang ${ }^{2,4, *}$ and $\mathrm{Yun} \mathrm{Hu}^{2,4}$ \\ 1 School of Mechatronics Engineering, Nanchang University, Nanchang 330031, China; \\ derickso@email.ncu.edu.cn (B.S.); yfluo@ncu.edu.cn (Y.L.) \\ 2 Key Laboratory of Silicon Materials in Colleges of Jiangxi Province, Xinyu 338004, China; \\ raosenlin@xyc.edu.cn (S.R.); 415926617082@email.ncu.edu.cn (Y.H.) \\ 3 School of Mechatronics \& Vehicle Engineering, East China Jiaotong University, Nanchang 330031, China \\ 4 School of New Energy Science and Engineering, Xinyu University, Xinyu 338004, China \\ * Correspondence: zhangfayun@xyc.edu.cn
}

Received: 16 November 2019; Accepted: 3 December 2019; Published: 23 December 2019

\begin{abstract}
Melt convection during the directional solidification process of multi-crystalline silicon plays a critical role in the transport of impurities. The utilization of a static magnetic field is an effective way to control the melt convection pattern. Studying the effect of the Lorentz force induced by the vertical magnetic field (VMF) on the melt convection of silicon in detail is beneficial to optimize the magnetic field parameters in the production process. Based on the numerical simulation method of multi-physics coupling, this paper explores the effects of different VMF intensities on the convection of silicon melt and the transport of oxygen in the melt during the directional solidification of polycrystalline silicon. The results show that in the first 125 minutes of the crystallization stage, the melt convection velocity is affected significantly by the magnetic field intensities. When different convection circulations are present in the silicon melt, the upper circulation easily transports oxygen to the furnace atmosphere, and the subjacent circulation easily lead to the retention and accumulation of oxygen. Enhancing the VMF intensity to a certain extent can reduce the size of the oxygen retention region in the silicon melt, and the time of the first disappearance of the subjacent circulation near the sidewall of the crucible is shortened. Then the average oxygen concentration in the silicon melt can be reduced. However, a larger vertical magnetic field intensity can result in greater average oxygen concentration in the oxygen retention region.
\end{abstract}

Keywords: directional solidification; multi-crystalline silicon; melt convection; oxygen impurity; numerical simulation

\section{Introduction}

Directional solidification technology is widely used in the production process of polycrystalline silicon ingots [1]. Impurities such as oxygen, carbon, and metals will be inevitably introduced during directional solidification in silicon. The content of impurities effects seriously on the generation of defects such as dislocations in silicon ingot [2,3]. Controlling the content of impurities in the polysilicon can improve the properties of the silicon wafers [2,4]. Recently, lots of studies have indicated that optimizing the solidification process can reduce the impurity in polysilicon [5-12]. Factors like growth rate [10], the power ratio of heaters [13,14] and the magnetic field [15-18] affect the content of impurities in the silicon significantly. 
Oxygen is commonly present in polysilicon ingots. Oxygen impurity can lead to many defects in the crystal [8,19-21], which deteriorates the performance of solar cells. The convection in silicon melt can be effectively controlled by adding a magnetic field to the directional solidification system [22], achieving the purpose of reducing impurity in the crystal $[11,18]$. At present, there are seldom studies that focus on the effect of static magnetic field on the production of polysilicon by directional solidification. Researchers $[18,23]$ were interested in the effect of the combination of electromagnetic field stirring and static magnetic field in a silicon directional solidification process. The influence on melt convection, melt-crystal interface shape [23], and impurity distribution [18] were discussed in detail. But the effect when only the static magnetic field is present is not investigated in these papers. The application of a vertical or horizontal magnetic field [24] significantly affects the mixing of melt, and both of them have a good performance, and so decrease the interface deflection in a directional solidification system of polysilicon. However, melt convection and impurity transportation in silicon melt during the time evolution of crystallization under the effect of VMF are not investigated profoundly in recent years.

In this paper, by using commercial software COMSOL Multiphysics, the effect of VMF on the melt convection and oxygen transport in silicon melt during directional solidification was investigated by numerical simulation. The results show that the VMF can affect the size of the melt convection circulations at different positions in the silicon melt during directional solidification, and can also affect the transportation of oxygen in different circulations in the silicon melt.

\section{Model Description and Calculation Method}

\subsection{Directional Solidification System}

The process of directional solidification mainly includes the heating and melting, molten state, crystallization, annealing and cooling stages of the polysilicon. The purpose of the molten stage before crystallization is to melt the silicon sufficiently. In this paper, the molten state and crystallization stages were simulated numerically by the commercial software COMSOL Multiphysics, with the molten state stage of about 40 minutes and the crystallization stage of about 180 minutes. The phenomena in the crystallization stage were investigated in detail.

The directional solidification system employed in our model was simplified to two-dimensional axisymmetric, as shown in Figure 1. Components 1-12 constitute the directional solidification furnace, components $14-15$ constitute the magnetic field generating device, and component 13 is the atmosphere domain between them. The main components of the directional solidification furnace include polysilicon, quartz crucible, graphite crucible susceptor, heater, argon gas, insulation and so on. The core component in the magnetic field generating device is the coils that generate a magnetic field in the current state. During crystallization, the crucible moves downward, so that the cooling rate at the bottom of the crucible is accelerated, and the temperature difference in the vertical direction is formed in the silicon to achieve the purpose of directional solidification.

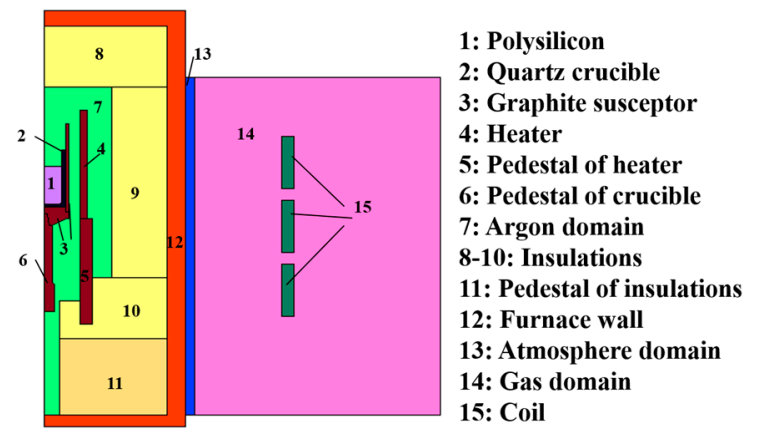

Figure 1. Schematic diagram of the directional solidification system. 
The model was divided by free triangle meshes in which the melt domain was calibrated by "fluid dynamics" and the mesh was refined at the boundary. The refined mesh was used in domains like polysilicon, crucible, and argon where high calculation accuracy was required, and the coarse mesh was used in domains where the calculation accuracy was relatively low, to save the calculation cost on the premise of ensuring the calculation accuracy of the main areas. The initial mesh quality of the directional solidification system which measured by the qual-condition value is shown in Figure $2 a$, where a value of 1 indicates the highest mesh quality. Figure $2 b$ shows the variation of the qual-condition value of the mesh during the molten state and crystallization stages. The minimum qual-condition value of mesh quality is always above 0.85 , and the average value remains above 0.98 . Therefore, the mesh settings in this model can be considered reasonable.
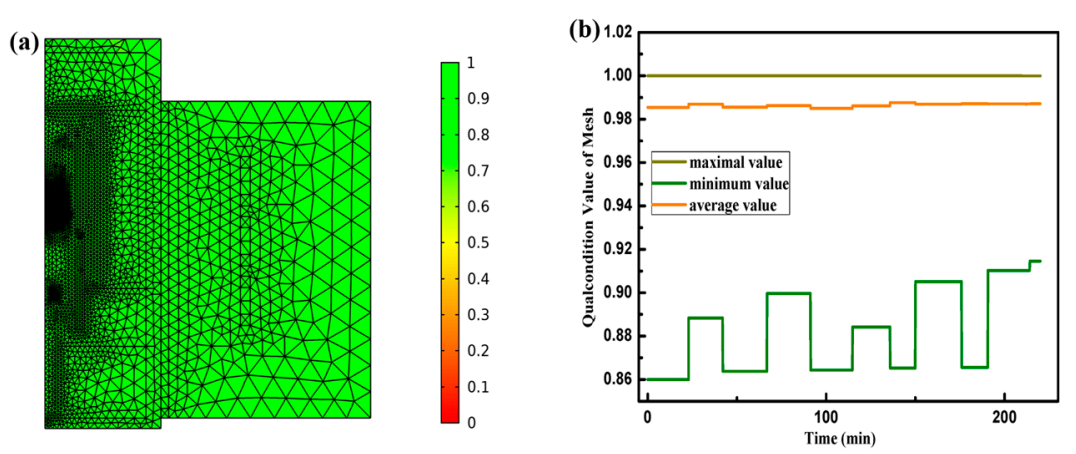

Figure 2. Mesh quality: (a) the initial mesh quality; (b) qual-condition value of the mesh.

\subsection{Calculation Method}

In this study, a global transient model that coupled physical fields such as thermal field, magnetic field, melt convection and impurity transport was established. The moving mesh module was employed to simulate the downward movement of the crucible during the crystallization process. In this simulation, the radius of polysilicon is $22.5 \mathrm{~mm}$, and the height of silicon is $50 \mathrm{~mm}$. The major assumptions in this model are as follows $[7,25,26]$ : (1) in order to save the calculation cost, the influence of the flow of argon gas in the furnace chamber on heat transfer is neglected; (2) silicon melt is laminar flow and incompressible; (3) the surface in which the components are in contact with argon is regarded as a diffuse reflection gray surface by considering the effect of radiative heat transfer; and (4) the section whose temperature is lower than $1685 \mathrm{~K}$ in the silicon is crystal, and the rest is melt.

The equation for the calculation of conductive heat transfer and convective heat transfer is [27]:

$$
\rho C_{p} \frac{\partial T}{\partial t}+\rho C_{p} \vec{u} \nabla T-\nabla \cdot(k \nabla T)=Q
$$

where $T$ is temperature, $\rho$ is density, $C_{p}$ is the specific heat, $k$ is thermal conductivity, $\vec{u}$ is the flow velocity and its value is 0 in solid heat conduction, and $Q$ is the heat source term. Radiation heat transfer is calculated by the following equation:

$$
\begin{gathered}
-\vec{n} \cdot(-k \nabla T)=\varepsilon\left(G-\sigma T^{4}\right) \\
(1-\varepsilon) G=J-\varepsilon \sigma T^{4}
\end{gathered}
$$

where $G$ is irradiation, $\sigma$ is the blackbody radiation constant, $\varepsilon$ is the emissivity and $J$ is radiosity [27].

Factors such as density, temperature difference, and Lorentz force will affect convection in the silicon melt. The contact surface between the silicon melt and the crucible wall surface adopts the condition of the no-slip boundary, and the velocity at the contact surface is 0 . The top surface of the silicon melt considers as an open boundary, and the pressure at the surface is consistent with the 
pressure value of the atmosphere in the furnace. The convection in the silicon melt is mainly controlled by the following equations [1,16]:

$$
\begin{gathered}
\rho \nabla \cdot(\vec{u})=\rho \nabla \cdot(\vec{u})=0 \\
\rho\left[\frac{\overrightarrow{\partial u}}{\partial t}+(\vec{u} \cdot \nabla) \vec{u}\right]=-\nabla p+\nabla \cdot\left[\mu\left(\nabla \vec{u}+(\nabla \vec{u})^{T}\right)\right]+\vec{F}_{v}+\vec{J} \times \vec{B}
\end{gathered}
$$

where $p$ and $\mu$, are pressure and dynamic viscosity, and $\vec{F}_{v}$ is volume force in the melt when no magnetic field is applied $[1,28]$. The density in the silicon melt $[29,30]$ is $\rho=3194-0.3701 T . \vec{J} \times \vec{B}$ is Lorentz force term, where $\vec{J}$ is the current density and $\vec{B}$ represents the magnetic field. The current density $\vec{J}$ is calculated by Ohm's law:

$$
\vec{J}=\sigma(\vec{E}+\vec{u} \times \vec{B})
$$

In our calculation, the oxygen mainly dissolved from the crucible wall by considering the chemical reaction between the $\mathrm{Si}_{3} \mathrm{~N}_{4}$ coating and the silica crucible [6]. The governing equation for the transfer of oxygen atoms in the silicon melt is [7].

$$
\vec{u} \nabla C=D \nabla(\nabla C)
$$

where $C$ and $D$ are the oxygen concentration and diffusion coefficient $\left(D=5 \times 10^{-8} \mathrm{~m}^{2} / \mathrm{s}\right)$. The equilibrium concentration of oxygen near melt-crucible interface is $[7,31]$

$$
\begin{gathered}
C_{o}=0.5 \times 10^{23} \times \frac{a_{o}}{\left(1-a_{0}\right)}\left(\text { atoms } / \mathrm{cm}^{3}\right) \\
a_{0}=1.32 \times \exp \left(-\frac{7150}{T}-6.99\right)
\end{gathered}
$$

where $C_{o}$ is oxygen near the melt-crucible interface. Oxygen is transported in the silicon melt and diffuses into the argon through the upper surface of the melt. The evaporation rate coefficient $\varepsilon(T)$ at the melt surface is $[7,32]$

$$
\varepsilon(T)=5.9152 \times 10^{7} \exp \left(\frac{-4.1559 \times 10^{4}}{T}\right)(\mathrm{m} / \mathrm{s})
$$

The calculation of this simulation only considered the transport of oxygen in the silicon melt. The calculation of the oxygen accumulation in the silicon crystal was neglected.

The material parameters of the components in this study are mainly from the references $[5,22,29]$.

\section{Control of Magnetic Field}

A direct current is applied to the coil of the magnetic field generating device, and the current magnitudes are $1 \mathrm{~A}, 10 \mathrm{~A}$, and $20 \mathrm{~A}$, respectively, so that a static magnetic field is generated in the ingot furnace. Figure 3 a shows the direction of the magnetic field in the directional solidification furnace, and Figure $3 \mathrm{~b}$ shows the direction of the magnetic field in the silicon. It can be thought that the polysilicon is in a magnetic field that is vertically upward during the crystallization process.

During the crystallization stage, the silicon and the crucible moves downward in the vertical direction. Therefore, the magnitude of the magnetic field in silicon changes over time during solidification. The average value of the magnetic flux density in the silicon during crystallization is shown in Figure 4. The intensity of the magnetic field in the silicon is gradually increased during the crystallization process. On the subsequent description in this paper, when referring to the magnitude of the current in the coil, it is essential to indicate the magnetic flux density in silicon shown in Figure 4. 
(a)

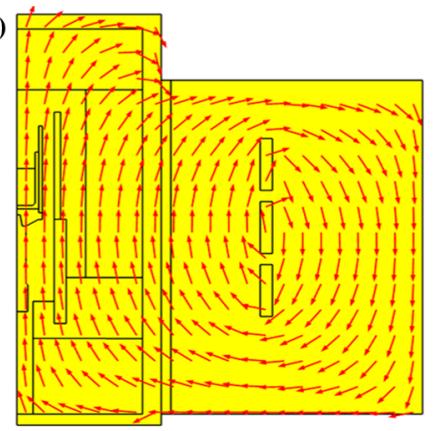

(b)

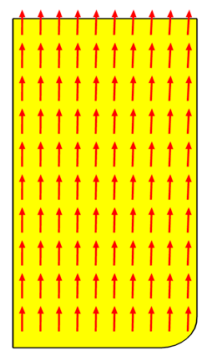

Figure 3. Direction of the magnetic field in the directional solidification system: (a) magnetic field in the total system; (b) magnetic field in the silicon.

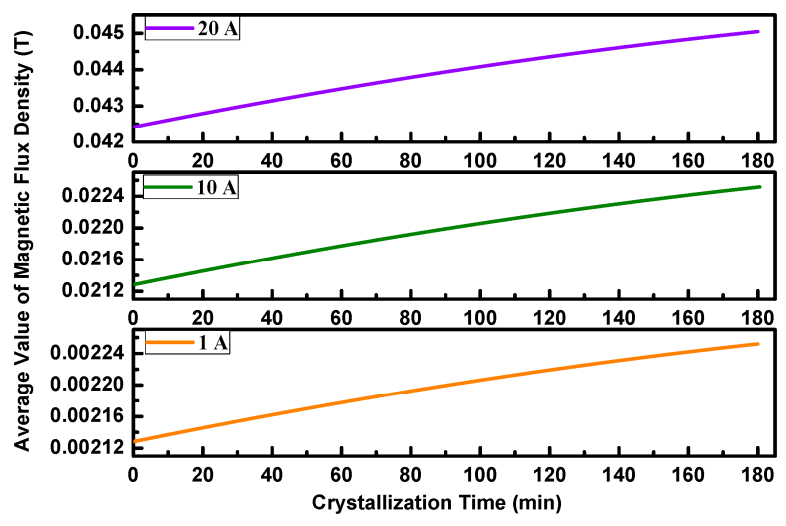

Figure 4. The average value of the magnetic flux density in the silicon during crystallization.

\section{Results and Discussion}

In this study, different time of crystallization was selected as the illustration to analyze the effects of magnetic flux density of VMF on the melt convection and oxygen transportation in silicon melt. Figure 5 shows the Lorentz force and melt flow velocity in the silicon melt at the beginning, the 45th minute, the 90th minute and the 120th minute of the crystallization stage. The left side shows the magnitude and direction of the radial component of the Lorentz force. The value less than 0 indicates that the Lorentz force is directed to the center of the melt, a value greater than 0 indicates that the Lorentz force is directed to the sidewall of the crucible. The right side shows the melt velocity. The bottom gray region in subgraphs (ii)-(iv) indicate the silicon crystal. The maximum melt convection velocity occurs at the upper section of the melt due to factors such as the size of the silicon melt and the volume force, and the melt velocity at the interface between the melt and the crucible is zero. The melt velocity in the silicon melt is greatly affected by the Lorentz force.

Figure 6 shows the value of the maximum melt convection velocity in the silicon melt during crystallization. It implies that when the crystallization time is before the 125th minute, the flow velocity of the silicon melt is significantly affected by the magnetic field. The greater the intensity of the magnetic field, the lower the melt velocity. In addition, the convection velocity of the melt is too small in the late stage of crystallization, so that the influence of the Lorentz force on the melt is significantly weakened. After 125 minutes of crystallization, there exists an insignificant difference in melt convection velocity in Figure 6. 

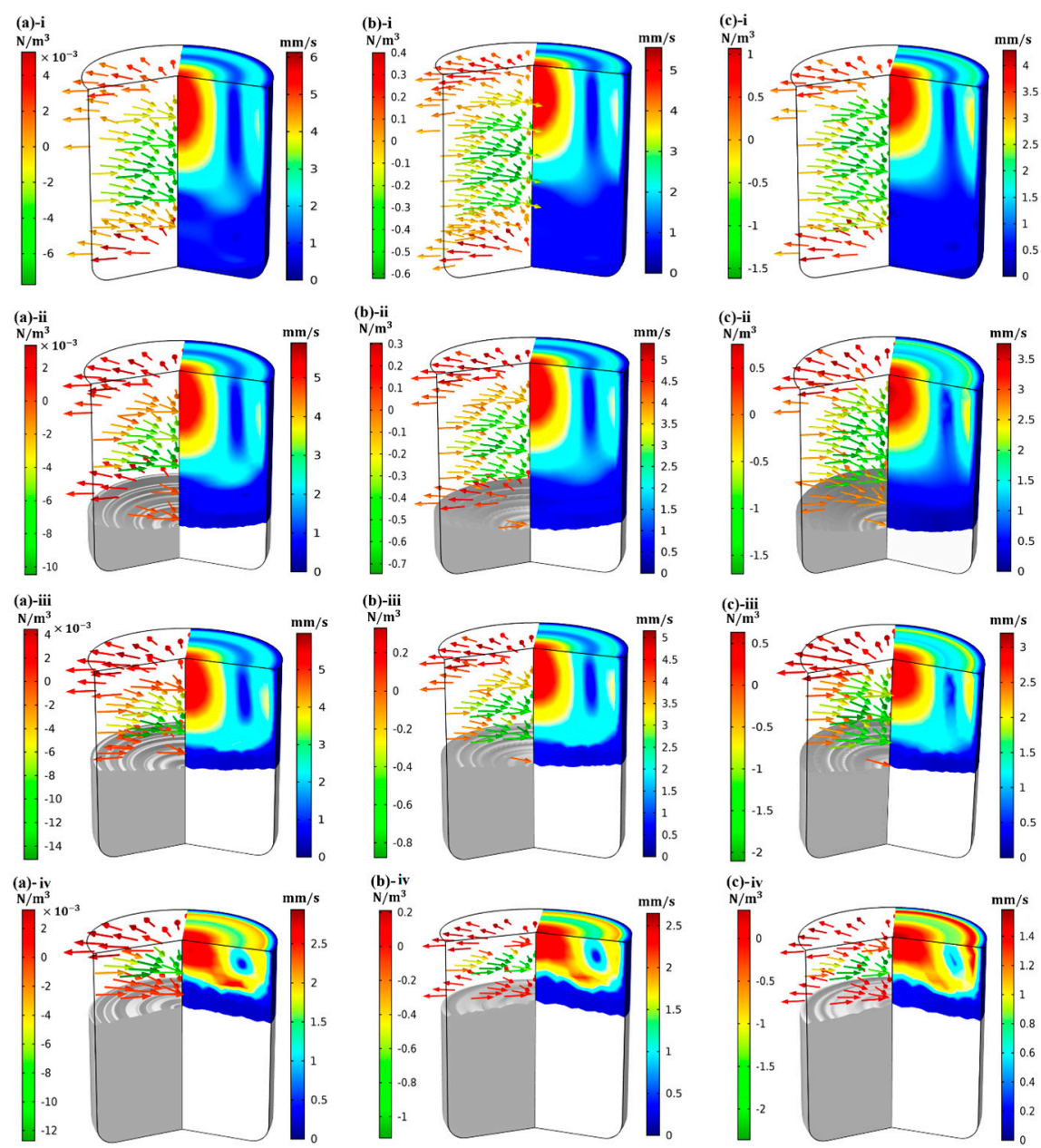

Figure 5. Lorentz force (left) and melt flow velocity (right) in the silicon melt when the current magnitude is: (a) $1 \mathrm{~A}$, (b) $10 \mathrm{~A}$, and (c) $20 \mathrm{~A}$ at (i) the beginning, (ii) the 45th minute, (iii) the 90th minute, and (iv) the 120th minute of the crystallization stage.

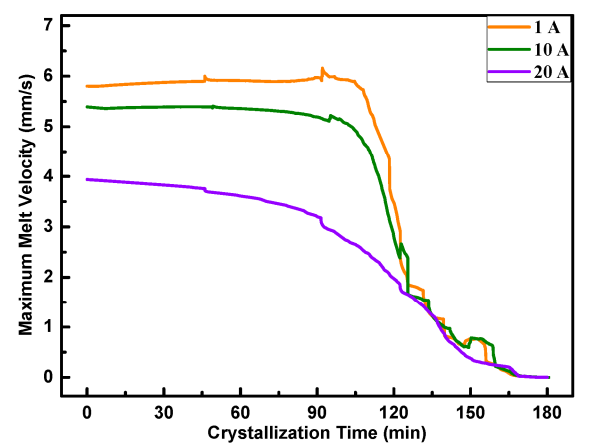

Figure 6. The value of the maximum melt convection velocity in the silicon melt.

The VMF affects the convection in the silicon melt and simultaneously affects the transport of oxygen in the melt. Oxygen impurity comes from the contact surface between the silicon melt and the crucible wall [7]. Convection in silicon melt plays an important role in oxygen transportation.

Figure 7 shows the direction and intensity of melt convection velocity (left) and oxygen distribution (right) in the silicon melt at the beginning, the 45th minute, and the 90th minute of the crystallization stage. At the beginning of crystallization, two main convection circulations are present in silicon melt. The upper melt convection circulation flows upwards near the sidewall of the crucible, and the 
oxygen in the circulation mainly comes from the crucible wall and the lower circulation, and most of the oxygen will be transported to the top surface of melt to the furnace atmosphere. The lower melt convection circulation flows downward near the sidewall of the crucible, and the melt carries oxygen from the crucible wall into the circulation. Part of the oxygen in the lower circulation is transported to the upper circulation through the junction of the upper and lower circulations, and the rest is recycled to the subjacent circulation to cause oxygen accumulation. Thus, the oxygen content in the lower circulation is significantly greater than the upper circulation.

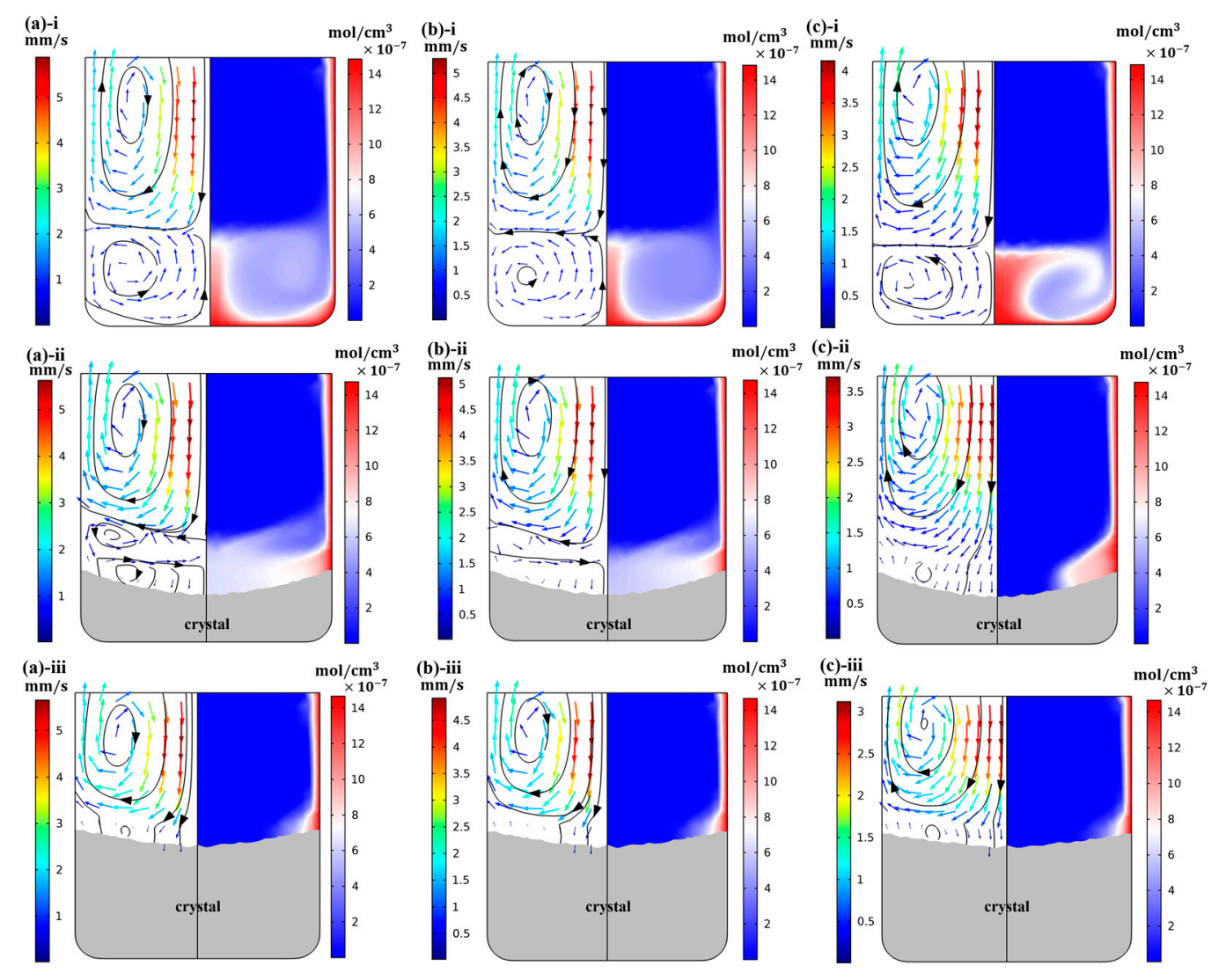

Figure 7. The direction and intensity of melt convection velocity (left) and oxygen distribution (right) in the silicon melt when the current magnitude is: (a) $1 \mathrm{~A}$, (b) $10 \mathrm{~A}$, and (c) $20 \mathrm{~A}$ at (i) the beginning, (ii) the 45th minute, and (iii) the 90th minute of the crystallization stage.

For convenience of description, the circulation region in the melt which easily transports oxygen to the top surface of the melt is defined as the oxygen transport region, and the circulation region which is disadvantageous for transporting oxygen out of the melt is defined as the oxygen retention region. Obviously, the lower circulation is the oxygen retention region.

When the current magnitude is $1 \mathrm{~A}$ in coil, the size of lower circulation is the largest and the melt flow direction is complicated. When the current magnitude is $20 \mathrm{~A}$, the size of lower circulation is the smallest, and the melt flow direction is more regular. With the crystallization process, the size of lower circulation in silicon melt gradually becomes smaller. The oxygen concentration distribution illustrates that the size of the oxygen retention region in the melt is smaller when the current magnitude is $20 \mathrm{~A}$, but its average oxygen concentration is obviously higher in the oxygen retention region.

The area near the sidewall of the crucible is defined as the area in the silicon melt that is less than $4.25 \mathrm{~mm}$ from the sidewall of the crucible. Figure 8 shows the maximum value of the flow velocity of the silicon melt in the vertical direction near the sidewall of the crucible in the crystallization stage. The positive value indicates that the direction is upward, appears in the upper circulation region. The negative value indicates the direction downward, which appears in the lower circulation region 
near the crucible. From Figure 8a, it can be inferred that when the current is $1 \mathrm{~A}$, oxygen in the upper circulation in the silicon melt is more easily transmitted to the top surface of the melt. It can be inferred from Figure $8 \mathrm{~b}$ that the size of lower circulation near the sidewall of the crucible decreases with the crystallization time until it disappears. When the coil current is $1 \mathrm{~A}, 10 \mathrm{~A}$ and $20 \mathrm{~A}$, the time required for the first disappearance of the lower circulation near the sidewall is about 65 mins, 60 mins, and 47 mins, respectively. However, when the crystallization time is about 110 mins, the vertical flow velocity in the downward direction begins to appear again near the sidewall of the crucible, and the absolute value of the velocity tends to increase first and then decrease as shown in Figure 8b. Implying that during this stage, there will be a new lower circulation in the silicon melt near the sidewall of the crucible.
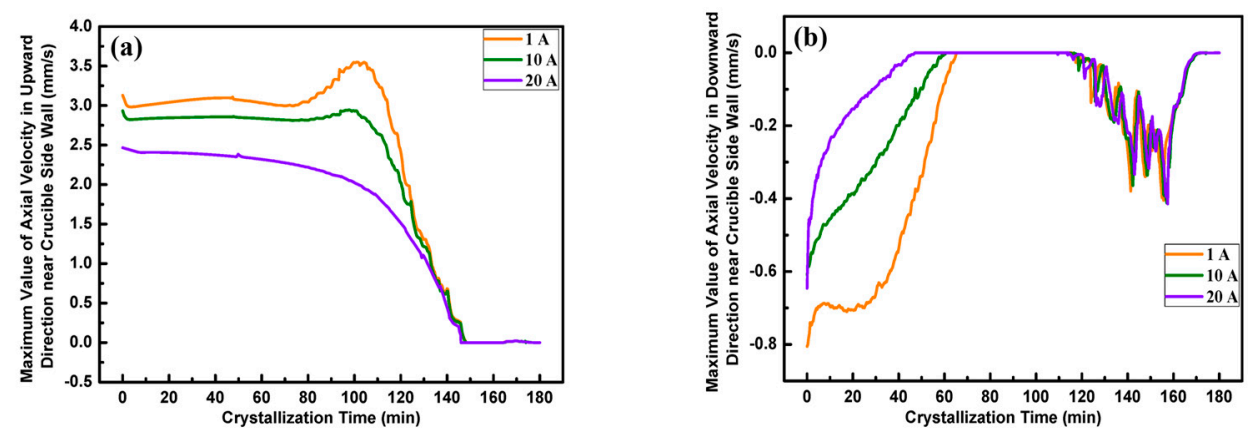

Figure 8. The maximum value of the flow velocity of the silicon melt in the vertical direction near the sidewall of the crucible in the crystallization stage: (a) the direction is upward; (b) the direction is downward.

Figure 9 shows the average concentration of oxygen in the silicon melt during crystallization. It illustrates that since the size of the oxygen retention region gradually decreases during crystallization, the average oxygen concentration in the melt also gradually decreases. There will be a small increase in average oxygen concentration during the late stage of crystallization, which may be related to the re-generation of the lower circulation near the sidewall of crucible implied in Figure $8 b$. Increasing the strength of the magnetic field in the furnace will increase the average oxygen concentration in the oxygen retention region of the silicon melt, but the size of the oxygen retention region will decrease. Therefore, the total oxygen content in the silicon melt decreases. It can be inferred that, after the crystallization stage, the oxygen impurity content in the lower portion of the silicon ingot is larger when the coil current is $20 \mathrm{~A}$, but its overall oxygen content is smaller.

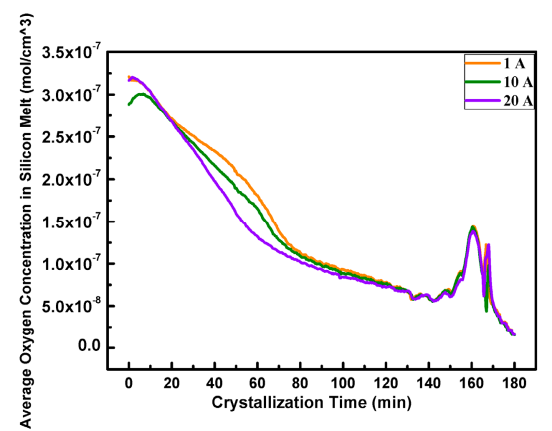

Figure 9. The average concentration of oxygen in the silicon melt.

\section{Conclusions}

During the directional solidification of polysilicon, the convection and the oxygen impurity transportation in the silicon melt can be affected obviously by adding a vertical magnetic field in the silicon region. The conclusions are as follows: 
(1) As the magnetic field intensity increases, the convection in the melt is more affected by the Lorentz force, and the melt convection velocity decreases significantly with the increase of the magnetic flux density. However, in the later stage of crystallization, the melt velocity is small enough that the effect of the Lorentz force on the convection is no longer significant.

(2) When the magnetic field intensity is small, the size of the oxygen retention region in the melt is larger, but the average oxygen concentration in the oxygen retention region is smaller. Increasing the magnetic field intensity, the size of the oxygen retention region in the melt becomes smaller, but the average oxygen concentration in the oxygen retention region is larger. However, increasing the intensity of the magnetic field is beneficial for reducing the total oxygen content in the silicon melt.

Author Contributions: B.S. and Y.L. developed the mathematical model, performed the numerical simulations, and analyzed the results; S.R. and F.Z. provided the information about the furnace structure and operating conditions for crystal growth. Y.H. checked the grammar issues. All authors took part in the writing and discussion processes. All authors have read and agreed to the published version of the manuscript.

Funding: This research was funded by the National Natural Science Foundation of China (No.51664047).

Conflicts of Interest: The authors declare no conflict of interest.

\section{References}

1. Li, J.D.; Chen, Y.F.; Hong, R.J. Modeling and optimization of the feedstock melting for industrial photovoltaic multi-crystalline silicon ingot. Sol. Energy 2016, 139, 108-115. [CrossRef]

2. Gao, B.; Nakano, S.; Kakimoto, K. Reducing impurities of multicrystalline silicon in a unidirectional solidification furnace for solar cells. JOM 2011, 63, 43-46. [CrossRef]

3. Ide, T.; Harada, H.; Miyamura, Y.; Imai, M.; Nakano, S.; Kakimoto, K. Relationship between dislocation density and oxygen concentration in silicon crystals during directional solidification. Crystals 2018, 8, 244. [CrossRef]

4. Gao, B.; Chen, X.J.; Nakano, S.; Kakimoto, K. Crystal growth of high-purity multicrystalline silicon using a unidirectional solidification furnace for solar cells. J. Cryst. Growth 2010, 312, 1572-1576. [CrossRef]

5. Teng, Y.Y.; Chen, J.C.; Huang, B.S.; Chang, C.H. Numerical simulation of impurity transport under the effect of a gas flow guidance device during the growth of multicrystalline silicon ingots by the directional solidification process. J. Cryst. Growth 2014, 385, 1-8. [CrossRef]

6. Teng, Y.Y.; Chen, J.C.; Lu, C.W.; Chen, H.I.; Hsu, C.; Chen, C.Y. Effects of the furnace pressure on oxygen and silicon oxide distributions during the growth of multicrystalline silicon ingots by the directional solidification process. J. Cryst. Growth 2011, 318, 224-229. [CrossRef]

7. Nakano, S.; Gao, B.; Kakimoto, K. Relationship between oxygen impurity distribution in multicrystalline solar cell silicon and the use of top and side heaters during manufacture. J. Cryst. Growth 2013, 375, 62-66. [CrossRef]

8. Kesavan, V.; Srinivasan, M.; Ramasamy, P. Optimizing oxygen impurities using different heater design in the directional solidification of multi-crystalline silicon. Mater. Res. Express 2019, 6, 106323. [CrossRef]

9. Liu, L.J.; Ma, W.C.; Qi, X.F.; Li, Z.Y.; Zhang, Y.F. Global simulation of coupled oxygen and carbon transport in an industrial directional solidification furnace for crystalline silicon ingots: Effect of crucible cover coating. Int. J. Heat. Mass. Tran. 2017, 108, 2355-2364. [CrossRef]

10. Trempa, M.; Reimann, C.; Friedrich, J; Muller, G. The influence of growth rate on the formation and avoidance of $\mathrm{c}$ and $\mathrm{n}$ related precipitates during directional solidification of multi crystalline silicon. J. Cryst. Growth 2010, 312, 1517-1524. [CrossRef]

11. Dadzis, K.; Vizman, D.; Friedrich, J. Unsteady coupled 3d calculations of melt flow, interface shape, and species transport for directional solidification of silicon in a traveling magnetic field. J. Cryst. Growth 2013, 367, 77-87. [CrossRef]

12. Su, W.J.; Li, C.; Qi, X.F.; Yang, W.; Wang, J.F. Numerical analysis and optimization of gas flow and impurity control in directional solidification multi-crystalline si. J. Cryst. Growth 2019, 527, 125244. [CrossRef]

13. Li, Z.Y.; Liu, L.J.; Liu, X.; Zhang, Y.F.; Xiong, J.F. Heat transfer in an industrial directional solidification furnace with multi-heaters for silicon ingots. J. Cryst. Growth 2014, 385, 9-15. [CrossRef] 
14. Chen, W.L.; Wu, Z.Y.; Zhong, G.X.; Ding, J.J.; Yu, Y.Y.; Zhou, X.C.; Huang, X.M. Optimization of heat transfer by adjusting power ratios between top and side heaters for casting high-performance multi-crystalline silicon ingots. J. Cryst. Growth 2016, 451, 155-160. [CrossRef]

15. Cablea, M.; Zaidat, K.; Gagnoud, A.; Nouri, A.; Delannoy, Y. Directional solidification of silicon under the influence of travelling magnetic field. J. Cryst. Growth 2014, 401, 883-887. [CrossRef]

16. Li, Z.Y.; Qi, X.F.; Liu, L.J.; Zhou, G.S. Numerical study of melt flow under the influence of heater-generating magnetic field during directional solidification of silicon ingots. J. Cryst. Growth 2018, 484, 78-85. [CrossRef]

17. Yu, Q.H.; Liu, L.J.; Li, Z.Y.; Su, P. Global simulations of heat transfer in directional solidification of multi-crystalline silicon ingots under a traveling magnetic field. J. Cryst. Growth 2014, 401, $285-290$. [CrossRef]

18. Popescu, A.; Vizman, D. Numerical study of the influence of forced melt convection on the impurities transport in a silicon directional solidification process. J. Cryst. Growth 2017, 474, 55-60. [CrossRef]

19. Moller, H.J.; Long, L.; Werner, M.; Yang, D. Oxygen and carbon precipitation in multicrystalline solar silicon. Phys. Status. Solidi. A 1999, 171, 175-189. [CrossRef]

20. Moller, H.J.; Funke, C.; Lawerenz, A.; Riedel, S.; Werner, M. Oxygen and lattice distortions in multicrystalline silicon. Sol. Energy Mater. Sol. Cells 2002, 72, 403-416. [CrossRef]

21. Gao, B.; Nakano, S.; Kakimoto, K. Reduction of oxygen impurity in multicrystalline silicon production. Int. J. Photoenergy 2013. [CrossRef]

22. Yu, Q.H.; Liu, L.J.; Li, Z.Y.; Shao, Y. Parameter study of traveling magnetic field for control of melt convection in directional solidification of crystalline silicon ingots. Int. J. Heat Fluid Flow 2018, 71, 55-67. [CrossRef]

23. Vizman, D.; Tanasie, C. Novel method for melt flow control in unidirectional solidification of multi-crystalline silicon. J. Cryst. Growth 2013, 372, 1-8. [CrossRef]

24. Tanasie, C.; Vizman, D.; Friedrich, J. Numerical study of the influence of different types of magnetic fields on the interface shape in directional solidification of multi-crystalline silicon ingots. J. Cryst. Growth 2011, 318, 293-297. [CrossRef]

25. Fang, H.S.; Wang, S.; Zhou, L.; Zhou, N.G.; Lin, M.H. Influence of furnace design on the thermal stress during directional solidification of multicrystalline silicon. J. Cryst. Growth 2012, 346, 5-11. [CrossRef]

26. Chen, X.J.; Nakano, S.; Kakimoto, K. Three-dimensional global analysis of thermal stress and dislocations in a silicon ingot during a unidirectional solidification process with a square crucible. J. Cryst. Growth 2010, 312, 3261-3266. [CrossRef]

27. Yang, X.; Ma, W.H.; Lv, G.Q.; Wei, K.X.; Luo, T.; Chen, D.T. A modified vacuum directional solidification system of multicrystalline silicon based on optimizing for heat transfer. J. Cryst. Growth 2014, 400, 7-14. [CrossRef]

28. Chen, J.C.; Chiang, P.Y.; Nguyen, T.H.T.; Hu, C.; Chen, C.H.; Liu, C.C. Numerical simulation of the oxygen concentration distribution in silicon melt for different crystal lengths during czochralski growth with a transverse magnetic field. J. Cryst. Growth 2016, 452, 6-11. [CrossRef]

29. Ding, C.L.; Huang, M.L.; Zhong, G.X.; Ming, L.; Huang, X.M. A design of crucible susceptor for the seeds preservation during a seeded directional solidification process. J. Cryst. Growth 2014, 387, 73-80. [CrossRef]

30. Ganesan, N.S.; Manickam, S.; Karuppanan, A.; Perumalsamy, R. Simulation analysis on impurity distribution in mc-si grown by directional solidification for solar cell applications. Int. J. Mater. Res. 2016, 107, 525-533. [CrossRef] 
31. Matsuo, H.; Ganesh, R.B.; Nakano, S.; Liu, L.J.; Kangawa, Y.; Arafune, K.; Ohshita, Y.; Yamaguchi, M.; Kakimoto, K. Thermodynamical analysis of oxygen incorporation from a quartz crucible during solidification of multicrystalline silicon for solar cell. J. Cryst. Growth 2008, 310, 4666-4671. [CrossRef]

32. Togawa, S.; Huang, X.M.; Izunome, K.; Terashima, K.; Kimura, S. Oxygen-transport analysis in czochralski silicon melt by considering the oxygen evaporation from the melt surface. J. Cryst. Growth 1995, 148, 70-78. [CrossRef]

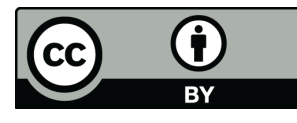

(C) 2019 by the authors. Licensee MDPI, Basel, Switzerland. This article is an open access article distributed under the terms and conditions of the Creative Commons Attribution (CC BY) license (http://creativecommons.org/licenses/by/4.0/). 